\title{
CRANIOPHARYNGIOMA: A CASE REPORT
}

Amandeep Chawla ${ }^{1}$, Shubhra Mehta ${ }^{2}$

\section{HOW TO CITE THIS ARTICLE:}

Amandeep Chawla, Shubhra Mehta. "Craniopharyngioma: A Case Report". Journal of Evolution of Medical and Dental Sciences 2014; Vol. 3, Issue 20, May 19; Page: 5445-5447, DOI: 10.14260/jemds/2014/2611

ABSTRACT: Craniopharyngioma is a type of brain tumor derived from pituitary gland embryonic tissue. It is also known as Rathkes pouch tumor. It is usually a suprasellar neoplasm with variable ocular presentation. We report an interesting case of a 30 year male presented to us with craniopharyngioma with optic atrophy and hemianopia. MRI brain showed presence of craniopharyngioma, survival rate are usually good with early detection and proper management.

KEYWORDS: Craniopharyngioma, MRI brain, Suprasellar neoplasm, Hemianopia, Rathkes Pouch.

INTRODUCTION: Craniopharyngioma is a type of brain tumor derived from pituitary gland embryonic tissue. ${ }^{1}$

It is also known as Rathke's pouch tumor. It is a rare, usually suprasellar neoplasm. ${ }^{2}$ It is a slow growing tumor which usually results in a bitemporal hemianopia due to compression of optic chiasma.

EPIDEMIOLOGY: Prevalence of craniopharyngioma varies world over, more common in USA, Japan, Africa and India. Its prevalence is approximately 2/100, 000 in America3. Overall it constitutes about $1-3 \%$ of intracranial tumors and $13 \%$ of suprasellar tumors. It is a common tumor seen in children, but adult form is also seen, slight male predominance exists in all groups.

ETIOLOGY: Two theories have been proposed for development of craniopharyngioma i.e.:

1. Embryogenetic theory in children

2. Metaplastic theory in adults

Beta catenine has been found to be as a marker for development of craniopharyngioma

CASE REPORT: A 30 year old male, non-vegetarian by diet presented to us with Gradual diminution of vision in both the eyes since 1 year Frontal headache since 1 month.

On Examination: Patient had best corrected visual acuity of Perception of light in right eye and 6/24 in left eye.

Right Eye showed fixed and semidilated pupil, not reacting to light along with corneal opacity. Intra Ocular Pressure of Right Eye was $16 \mathrm{~mm}$ [NCT] and left eye was: $15 \mathrm{~mm}$ [NCT].

Fundus picture showed presence of primary optic atrophy in Right Eye and partial optic atrophy in left eye [See Fig. 1]

Visual field of the Left Eye showed temporal hemianopia [See fig. 2]

MRI of brain showed a heterogeneous solid cystic mass, suprasellar mass lesion approximately $4.7 \times 3.7 \times 3.1 \mathrm{~cm}$ in size [See fig. 3] separate from pituitary gland and compressing the optic nerve suggestive of craniopharyngioma. The patient was referred to higher center for further management. 


\section{CASE REPORT}

DISCUSSION: Craniopharyngioma's are slow growing tumors which if detected early have a good prognosis. The survival rate in USA were approximately $86 \%$ at 2 years and $80 \%$ at 5 years after diagnosis, so early detection and proper management plays an important role in patient's survival. Subfrontal or trans-sphenoidal excision is usually recommended as surgical approach. Adjuvant radiotherapy and chemotherapy may be used if total surgical removal is not possible.

\section{REFERENCES:}

1. Craniopharyngioma at Dorlands medical dictionary.

2. Rodriguez FJ, Scheithauer BW, Tsunoda S, Kovacs K, Vidal S, Piepgras DG. The spectrum of malignancy in craniopharyngioma. Am J Surg Pathol. 2007 Jul; 31(7):1020-8.

3. Garnett MR, Pujet S, Grill j, Saint'e -Rose [2007]. Craniopharyngioma. Orphanet Journal of Rare Diseases 21.18 DOI: 10.1186/1750-1172-2-18.

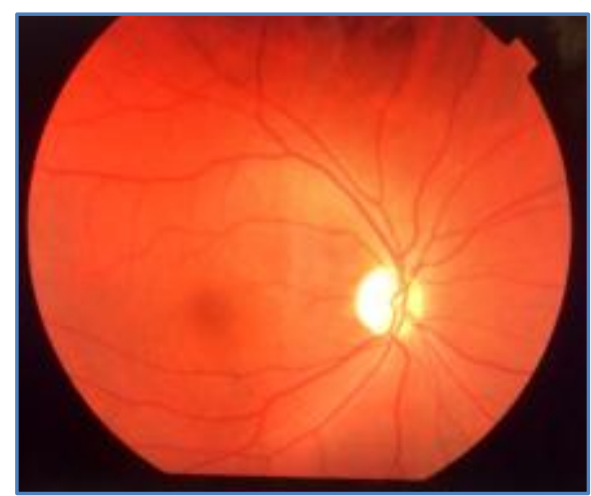

Figure: 1

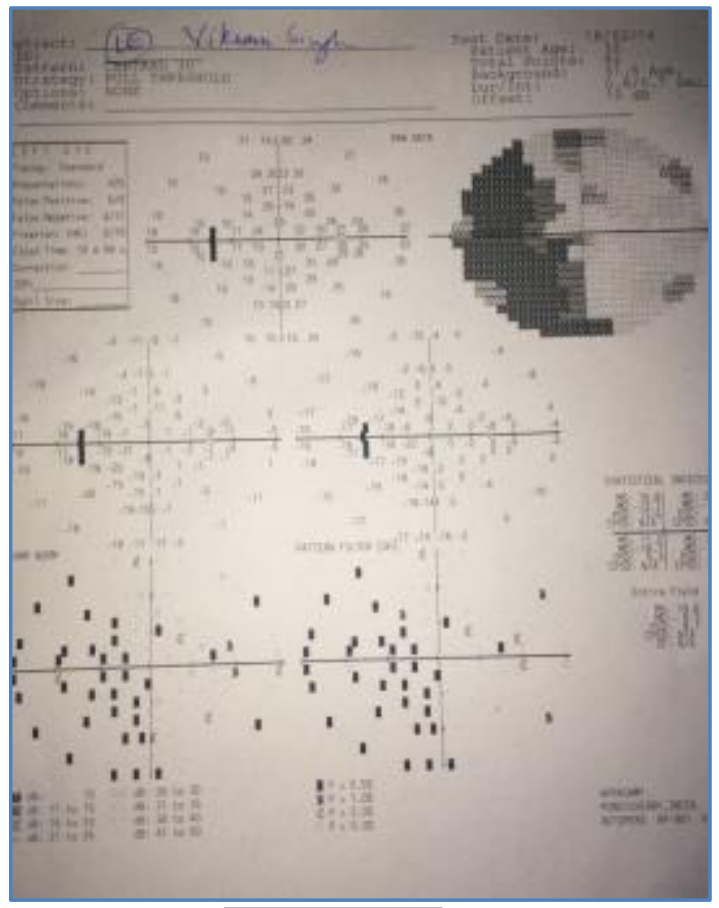

Figure: 3

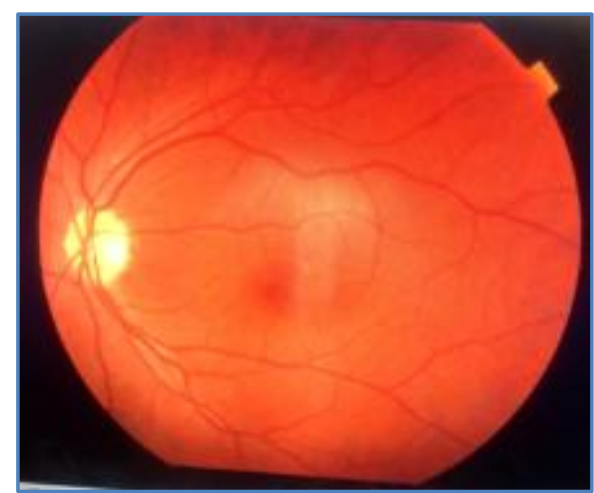

Figure: 2

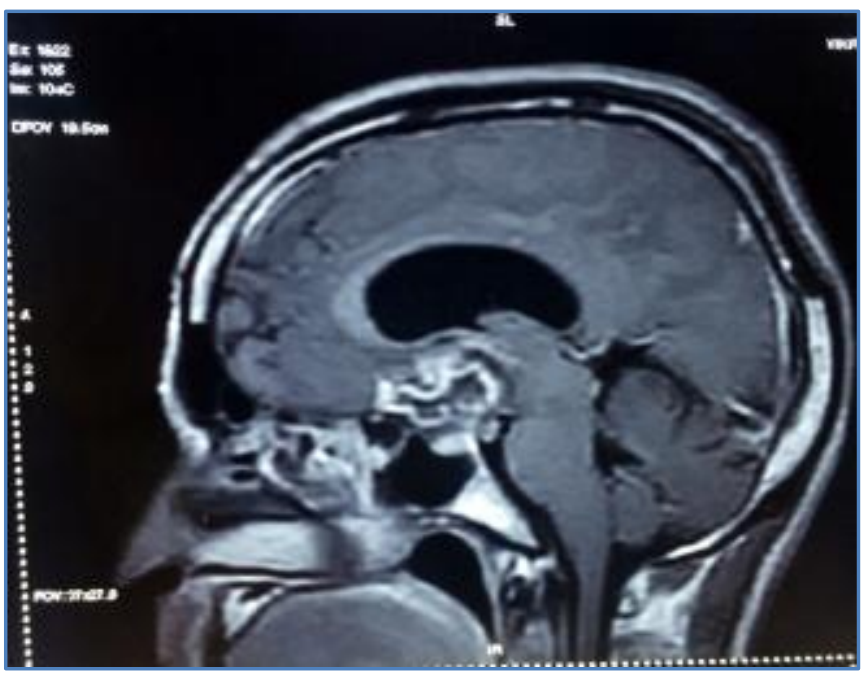

Figure: 4 


\section{CASE REPORT}

\section{AUTHORS:}

1. Amandeep Chawla

2. Shubhra Mehta

\section{PARTICULARS OF CONTRIBUTORS:}

1. $2^{\text {nd }}$ Year Post Graduate Student, Department of Ophthalmology, R. D. Gardi Medical College, Ujjain.

2. Associate Professor, Department of Ophthalmology, R. D. Gardi Medical College, Ujjain.

\section{NAME ADDRESS EMAIL ID OF THE} CORRESPONDING AUTHOR:

Dr. Amandeep Chawla, Room No. 106, RMO Hostel, R. D. Gardi Medical College, Ujjain.

Email: sunny_aman21@hotmail.com

Date of Submission: 25/04/2014. Date of Peer Review: 26/04/2014. Date of Acceptance: 05/05/2014.

Date of Publishing: 15/05/2014. 